\title{
TERRA, TEMPO E XENTE: AS ORIXES ALTOMEDIEVAIS DA COMARCALIZACIÓN DE GALICIA
}

\author{
Carlos Baliñas Pérez.
}

Universidade de Santiago de Compostela

No período chamado convencionalmente Alta Idade Media, a terra e os homes de Galicia son suxeitos duns procesos históricos que levarán á configuración dunha sociedade feudal no seu seo. Unha nova formulación social comporta, indefectiblemente, un novo modelo de relacións entre o ser humano e o medio natural en que desenvolve a súa existencia. Relacións que van para alén da mera ocupación física e explotación económica do territorio: dominar non é soamente posuír, senón tamén denominar, dar nome, integrar o posuído no universo mental e nas necesidades vitais do posuidor ou aspirante a tal. Por conseguinte, a xerarquización social do espazo humanizado implica, necesariamente, unha apropiación mental do solo. A ese proceso de mutua interrelación entre un espazo -Galicia- e os homes e mulleres que nel habitan -os galegos e galegas- ao longo dun tempo determinado, que poderiamos enmarcar cronoloxicamente entre os anos 700 e 1100 da nosa era, imos dedicar a nosa exposición, necesariamente sintética e aproximativa, recollendo as provisorias conclusións dun proceso de coñecemento e interpretación que levamos desenvolvendo dende hai bastantes anos ${ }^{1}$.

Tres son os niveis de denominación que determinan unha primeira e básica xerarquización do espazo humanizado polo home da Galicia altomedieval: o físico, o económico e o sociopolítico. O nivel físico fai referencia a un espazo natural diante do cal o individuo se coloca nun papel subordinado. Aínda así, trátase sempre dun medio bumanizado,

1 Sirva esta modesta achega de merecida homenaxe ao trixésimo aniversario do Atlas Lingüístico Galego e aos meus antigos compañeiros e compañeiras do Instituto da Lingua Galega e, en especial, ao inesquecible e desaparecido amigo Fernando Tato, a quen tanto botamos de menos.

R. Álvarez, F. Dubert, X. Sousa (eds.): Lingua e Territorio Santiago de Compostela: ILG/CCG, 2006, 93-101 ISBN 84-96530-20-5 
de espazos mediatizados pola acción humana ou contemplados dende esta perspectiva. A natureza virxe, á marxe das actividades humanas, chamada nas fontes silva ou eremum, non ten usualmente nome na sociedade galega da temperá Idade Media e está decote contemplada dende unha postura de descoñecemento, de distanciamento medoñento e de relativo desinterese diante dun medio hostil e improdutivo ${ }^{2}$. Os eixes básicos de estruturación deste nivel de denominación son, consonte o propio deseño axadrezado do mapa físico de Galicia e a insularidade da rede de poboamento altomedieval, os elementos naturais monte (separación, aproveitamento forestal e gandeiro) e río (conexión, fonte e regadío, cultivo) ${ }^{3}$. O nivel económico supón a referencia a un espazo natural transformado ou mediatizado pola intervención humana, diante do cal o individuo se sitúa nunha perspectiva de superioridade. Os elementos de referencia son o ager (flora domesticada, arrotea, transformación do medio, agricultura) e o saltus (vexetación natural pero instrumentalizada polo ser humano, silvicultura e gandería $)^{4}$. Finalmente, o nivel sociopoliti$c o$, no que a referencia a un espazo natural ten un papel secundario, pois son os homes e non o marco físico da súa vida cotiá o eixe vertebrador desta conceptualización do espazo. Os elementos referenciais son o poder e a xurisdición (a competencia sobre dos seres humanos derivada do xeito de organizarse estes en sociedade $)^{5}$.

Por suposto, estes tres niveis son complementarios e non excluíntes entre si, sendo habitual a súa superposición ou xustaposición sobre dun mesmo espazo. De feito, eles determinan a peza básica da definición territorial da Galicia altomedieval, o val, sexa este marcado

2 Et quam jam ut dixim locus ipse eremum erat et per vepribus et densarum silvarum absconsus jacebat, et nec eundi, nec redeundi ad ipsum locum viam vel semitam patefiebat (1007-04-23, reproducido en Duro Peña (1972). O texto refírese á futura localización do mosteiro de San Pedro de Rocas, no concello de Esgos, provincia de Ourense.

3 Villa vocabulo Cova... non procul a monte qui nuncupatur Scudris, iuxta rivulo Mero (935-058, Tumbo de Sobrado, ff. 44v-45r). Trátase da actual parroquia de Santo Tomé de Vilacoba, no concello coruñés de Abegondo.

4 Terras nostras proprias que habemus de nostris parentibus in villa Marciani de ripa Maiore, super domos Eldemiri, usque ad arborem et usque ad limitem de agro Ierici (887-09-9, Tumbo de Sobrado, fol. $32 \mathrm{v}$ ).

5 Annuit michi corde puro et mente devota ut tibi, domino meo, contestem hominem qui est de nostro comitatu Karnota nomine Trasmirus, cum filiis suis (1011-03-5, Tumbo A de Santiago, reproducido en López Ferreiro, Historia ..., t. II, ap. doc. nº LXXXIV). 
polo curso dun río, pola confluencia de varios, a pegada de antigos movementos oroxénicos ou glaciares ou o discorrer de depresións ou elevacións montañosas; o mesmo acontece, máis ou menos contemporaneamente, nas outras rexións do norte peninsular: cf. García de Cortázar (1982) e Calleja e Beltrán (2002). Os primeiros territorios medievais galaicos, innominados aínda, defínense na documentación e nas fontes escritas como espazos acoutados, limitados e individualizados por unha serie de elementos naturais claramente identificables ${ }^{6}$. Como imos amosar deseguido, dentro das denominacións territoriais teñen unha presenza fundamental os xeo-topónimos e, de todos os xeitos, para a localización dun campo, unha aldea, unha fortaleza ou unha igrexa, atópase case sempre a referencia ao río e ao monte, como identificación previa á súa situación nunha ou noutra bisbarra.

Este espazo físico individualizado con base en parámetros físicos e sociais, que é a peza básica do deseño comarcal da Galicia altomedieval, recibe nas fontes documentais o nome de territorium. Non existe un termo medio normativo na definición espacial destes territoria: hainos extensos e reducidos, e mesmo o seu marco espacial pode mudar co tempo. Non é infrecuente tampouco que unha mesma zona poida ter máis dun nome, coexistindo no tempo un nome máis antigo con outro máis recente, un de orixe natural e outro derivado da entidade de poboación máis importante da comarca ${ }^{7}$. Tamén constatamos na documentación a existencia dunhas circunscricións territoriais maiores, chamadas terras. Unha terra é unha gran comarca natural, que comprende no seu interior territorios menores: non poucas delas darán o seu nome nos séculos XI e XII a grandes condados reais ou a arciprestádegos eclesiásticos ${ }^{8}$. Se ben esta rede territorial manifesta unha

${ }^{6}$ Vestra baselica Sancti Vincenti Levite, qui est fundata in territorio inter Arnogia et Limia, prope villa nostra que dicent Sabuzedi, iusta arrogio que vocitant Sorga (922-09-26, Tumbo de Celanova, fol. 195r. Trátase do actual lugar de Sabucedo, na parroquia de San Pedro de Orille, concello de Verea, provincia de Ourense.

7 Concedo tibi ipsas villas in territorio Deza connomento (sic) Grava (1085-03-29, Tumbo de Oseira, ed. Miguel Romaní, doc. no 9. Refírese á actual parroquia de San Miguel de Graba, no concello pontevedrés de Silleda).

8 Exemplos de terras altomedievais que dan o seu nome a grandes circunscricións administrativas son Faro, Monterroso, Navia ou Ortigueira; o caso dos arciprestádegos é moi evidente no caso da rede eclesiástica da arquidiocese compostelá: Bergantiños, Besancos/Bezoucos ou Nendos. 
salientable estabilidade e permanencia no tempo e no espazo, hai, ao longo do período que estudamos, territorios que desaparecen, subsumidos noutros ou repartidos entre territorios veciños, ou que mudan de nome e equivalencia territorial, en resposta aos cambios ocorridos nas redes espaciais de poboamento, xestión económica e administración política ${ }^{9}$. Cronoloxicamente podemos distinguir dous momentos. No período entre os anos 750 e 850 a localización espacial que nos revelan as fontes documentais é, basicamente, de carácter insular, primando a referencia a marcos espaciais físicos de carácter primario, que se corresponden cun poboamento desartellado e cunha estruturación política do espazo galego aínda moi incipiente. Agás no caso singular do dominio monástico de Samos, as referencias a territorium son escasas e moi imprecisas xeograficamente. No período 850-950, prima unha localización espacial de carácter territorial que, de xeito diacrónico, deseña un primeiro mapa comarcal de Galicia, con bisbarras cada vez mellor definidas xeograficamente. Aínda que o proceso de formación e definición de territorios continúa ata fins do século XI, as grandes liñas mestras están xa establecidas con claridade para mediados do século $\mathrm{x}$.

No período 950-1100 constatamos unha mudanza significativa na información diplomática, que testemuña o desenvolvemento dunha localización espacial de carácter político: o espazo xeográfico de Galicia é obxecto dun novo deseño territorial baseado en circunscricións de carácter administrativo e político. Este novo modelo de ente territorial recibe nas fontes os nomes de comitatus, conmissus ou mandatione. Formalmente, un condado é unha circunscrición administrativa rexida por un comes ou conde, un magnate dependente directamente do monarca, cun rango social e unhas competencias maiores que as do rexente dun conmissus, quen non ten o título condal e parece ser de menor rango social e con atribucións políticas máis limitadas. A mandatione semella corresponderse co ámbito de xurisdición dun magnate local, que exerce funcións públicas de poder por delegación rexia. Teoricamente cando menos, esta escala decrecente en nivel social e poder corresponderíase cun ámbito espacial máis reducido. $\mathrm{Na}$ realidade dos feitos, a documentación amósanos que a distinción entre estes tres tipos de cir-

9 Un caso paradigmático é o dos territorios de Ferreira, Guntín e Pallares, por terras do actual concello lucense de Guntín. 
cunscrición administrativa é máis formal que real: hai casos de abondo constatados de, por exemplo, condes rexendo conmissos ou mandationes que comprenden comarcas naturais enteiras e de considerable tamaño ${ }^{10}$, e a propia documentación coetánea emprega ambivalentemente estes tres termos ${ }^{11}$. Por iso, falaremos xenericamente de condados ao referirnos a estas entidades administrativas. Un segundo aspecto que cómpre salientar é que, aínda partindo de concepcións espaciais ben distintas, a documentación revela unha manifesta identidade entre territorium e comitatum: nun $52,5 \%$ dos casos, un mesmo espazo é alcumado como territorio e como condado; se a iso lle sumamos os casos de condes que gobernan comarcas non descritas especificamente como comitatos, de territorios que se corresponden case con total exactitude con dous ou máis condados e viceversa, de circunscricións eclesiásticas calcadas espacialmente sobre bisbarras naturais e sobre as que os prelados ou abades exercen competencias de poder público ou estendemos a nosa pescuda ata os séculos XII e XIII -loxicamente, mellor documentados-, a porcentaxe de concorrencia entre comarcas naturais e comarcas administrativas elévase ata superar o $70 \%$. Dito doutro xeito: o condado calca o seu deseño sobre o da comarca natural.

Consonte o devandito, podemos establecer un listado de oitenta comarcas nas que se dividía o espazo xeográfico da Galicia altomedie$\mathrm{val}^{12}$. O marco referencial é a Galicia nuclear: exclúense, polo tanto, as comarcas pertencentes ao actual Portugal, pero inclúese o territorio do Bierzo, parte integral do territorio galego en toda a xeira medieval. Se procedemos a unha análise toponímica histórica destas bisbarras, podemos establecer a seguinte clasificación:

- Territorios de denominación hidrotoponímica. Estrutúranse arredor de vales fluviais ou confluencia de varios ríos. Xunto

${ }^{10}$ Conmissum rexido por condes ao longo dun período de tempo considerable: 991-0524, Flórez, España Sagrada, t. XIX, pp. 379-382.

${ }^{11}$ In mandatione que dicunt Presares (955-04-10, Tumbo de Sobrado, fol. 18r.). Isti sunt terminos de conmisso de Presares (¿955?, Tumbo de Sobrado, ff. 42v-43r.). Os seus gobernantes, Hermenegildo Alóitiz e Rodrigo Menéndez, son comites.

${ }^{12}$ Unha relación detallada pode atoparse en Baliñas (1992: 331-363) e Baliñas (1998: 262-289). Cómpre incluír o caso do territorio de Elenia, que toma o seu nome do río Ella ou das Ellas, por terras do actual concello ourensán de Cartelle, e coñecido pola documentación medieval de Celanova, que non está referido no devandito corpus. 
cos derivados da orografía, conforman o xeito máis primitivo e natural de artellamento de unidades comarcais. Constitúen unha porcentaxe elevada dos territorios coñecidos: vinte denominacións, o $25 \%$ dos nosos rexistros. Exemplos salientados son os casos de Deza, Arnoia, Ambasmestas ou Navia.

- Territorios de denominación oronímica. Teñen como base xeográfica a parcelación do espazo por elevacións montañosas. Aparecen documentados cinco casos, que supoñen un 6,25\% dos rexistrados. Exemplos salientados son Lobeira, Monterroso, Montaos ou Monseiro.

- Territorios de orixe histórica prerromana. Agrupamos neste apartado tanto as comarcas que teñen a súa orixe na distribución espacial dos grandes conxuntos étnicos de base xentilicia, ben orixinariamente, ben logo da súa redución e asentamento pola ocupación romana -casos de Céltigos, Lemos ou Valdeorras-, coma aquelas outras das que a súa toponimia e bases constitutivas proveñen de antes da romanización de Galicia -A Mahía, Abeancos, Trasancos-. Podemos documentar con seguridade quince rexistros, o $18,75 \%$ do total da mostra. Cómpre sinalar que moitos deles aparecen xa documentados a fins do século VI, segundo o Paroquiale Suevorum.

- Territorios de orixe histórica romana. Se ben os citados no anterior apartado o son tamén en certa medida, xuntamos aquí aquelas bisbarras que teñen a súa orixe na ordenación do territorio realizada durante a dominación imperial romana, tanto dende o punto de vista poboacional como económico ou infraestrutural. Aparecen documentados con certa seguridade dez casos, o $12,5 \%$ do total dos rexistros. Exemplos salientados serían os de Faro, Triacastela e, posiblemente, O Saviñao.

- Territorios de orixe histórica altomedieval. Agrupamos neste apartado todas aquelas denominacións territoriais non incluídas nos apartados anteriores e non documentadas antes da xeira que estudamos, as que teñen a súa orixe na apropiación do espazo pola sociedade altomedieval galega -coma Guntín ou Baroncelle- e na parella reorganización das estruturas administrativas e eclesiásticas -casos de Sete Igrexas, Celanova ou Ferreira-. Teñen todas elas como común denominador que a súa aparición, individuali- 
zación e desenvolvemento como circunscricións territoriais está en estreita relación co proceso de definición social e territorial de Galicia ao longo dos séculos VIII a XI. Comprenden trinta mencións, o $37,5 \%$ do total.

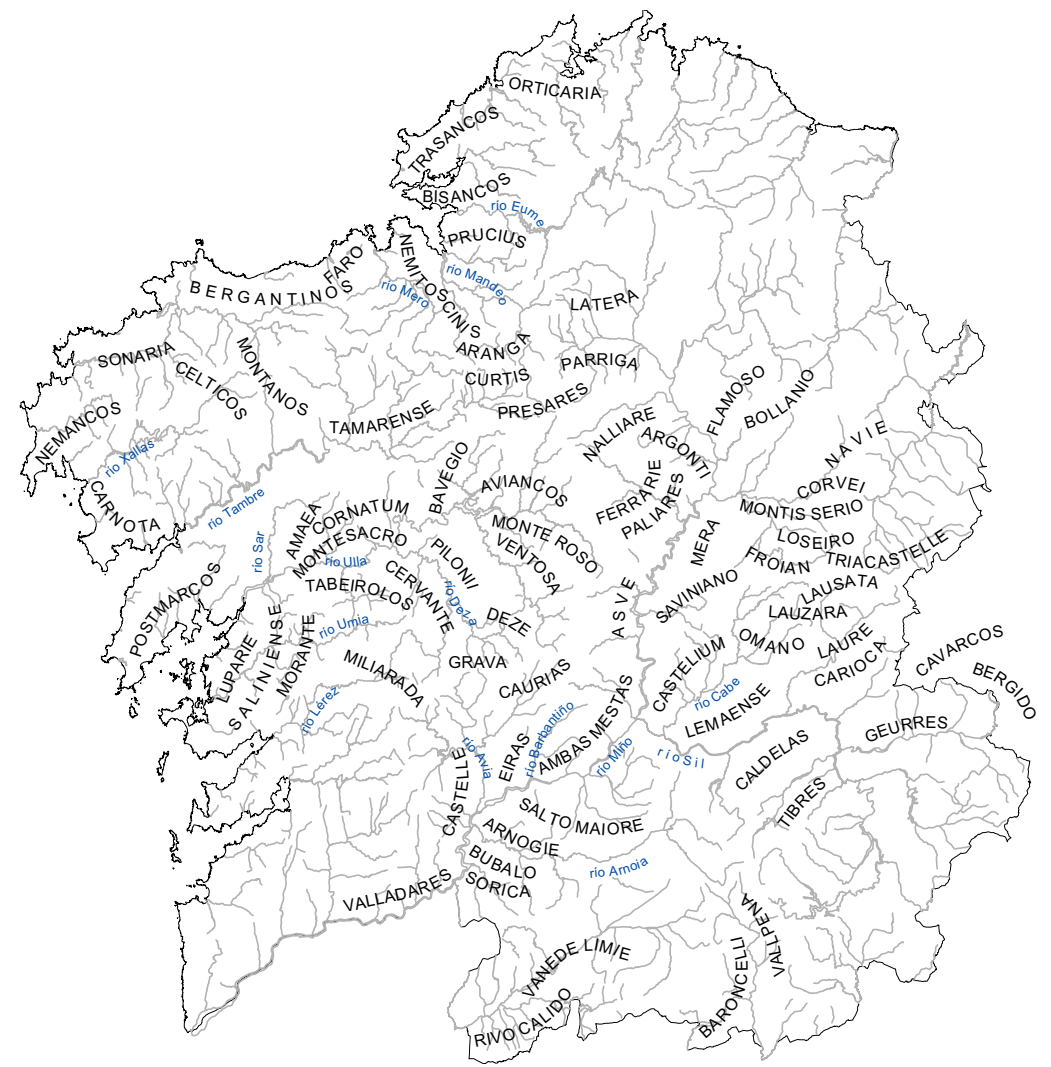

Mapa das circunscricións territoriais da Galicia altomedieval

Esta clasificación permítenos fundamentar unha serie de conclusións do maior interese para a nosa investigación. En primeiro lugar, podemos constar como os habitantes da Galicia do período 700-1100 recorren case por igual cara á estruturación comarcal do territorio ao deseño físico do espazo, a construcións espaciais herdadas do pasado e a novas configuracións derivadas das necesidades e demandas da conformación do ecosistema social altomedieval: cada un dos concep- 
tos cobre aproximadamente un terzo do total. En segundo lugar, é evidente o importante peso que o legado do pasado ten neste novo marco territorial, ben sexa a estruturación territorial de base xentilicia de orixe prerromana ou a ordenación do territorio herdada do dominio romano. Mais cómpre tamén salientar que esta herdanza do pasado queda lonxe de determinar e condicionar a vertebración espacial da Galicia altomedieval: soamente dezanove das comarcas documentadas no período que analizamos (un $23,75 \%$ do total) son identificables con seguridade no Paroquiale Suevorum de fins do século $\mathrm{VI}^{13}$. O artellamento comarcal da Galicia dos séculos IX a XI non é o resultado da evolución inmutable de esquemas precedentes, senón produto do deseño territorial específico dunha sociedade xerarquizada no seu camiño ao feudalismo que, ata cando recorre parcialmente a modelos anteriores, o fai mediante a integración transformadora nun sistema propio e axeitado ás súas necesidades e retos.

Outro aspecto significativo é o da distribución territorial das comarcas e circunscricións territoriais coñecidas. Vinte e sete delas atópanse na actual provincia de Lugo (33,75\%), vinte e catro na da Coruña (30\%), dezaoito na de Ourense $(22,5 \%)$ e soamente once na de Pontevedra (13,75\%). Se as agrupamos conforme á gran divisoria interior galaica, podemos ver que hai un claro desequilibrio a favor da Galicia oriental ou interior e que se detectan grandes baleiros na Mariña cantábrica e nas Rías Baixas. Cómpre ter en conta, á hora de avaliar estes datos, que a nosa información procede case exclusivamente dos grandes centros eclesiásticos e que a súa transmisión ata hoxe en día se ten visto afectada por diversos avatares históricos: por exemplo, non hai documentación altomedieval ou é moi escasa no relativo a Dumio-Mondoñedo, Tui e Lérez. Aínda así, estes datos correspóndense co que sabemos do poboamento da Galicia altomedieval, concentrado nos vales interiores e na ribeira dos grandes sistemas fluviais, mentres a beiramar parece estar moi pouco habitada ata as grandes repoboacións costeiras dos séculos XII e XIII. Consonte isto, o tecido comarcal semella

${ }^{13}$ Cf. texto en Pierre David (1947: 30-44; comentarios do autor en 45-82). Non imos entrar aquí no considerable debate historiográfico sobre da validez da fonte, conservada en varias versións discrepantes entre si, mais si indicar que nós apostamos pola pertinencia do seu uso, en tanto en canto as informacións nela contidas poidan contrastarse con outras de procedencia máis indiscutida. 
máis mesto -e dende época máis temperá- arredor dos grandes núcleos que vertebran política, económica e eclesialmente Galicia -Lugo, Santiago, Samos, Celanova e Sobrado- e que xogan o papel de grandes cabeceiras comarcais ou rexionais. Velaí o caso do territorium Lucensi, macro-estrutura administrativa case-provincial que abranguía os condados comprendidos entre os ríos Eo, Navia, Sil e Sor nos séculos X e $\mathrm{XI}^{14}$ ou do conxunto territorial que será posteriormente coñecido como Terra de Santiago. Tamén podemos constatar como os grandes centros eclesiásticos deseñan, dende moi cedo, unha auténtica rede de ordenación do territorio baseada nunha xerarquización das comarcas circundantes baixo da súa xurisdición, o que é moi patente nos casos das abadías de Samos e Celanova e da diocese de Iria-Santiago.

En resumo, e para rematar, entre os séculos IX e XI ten lugar a primeira e decisiva comarcalización de Galicia, a primeira ordenación integral e completa das terras e dos homes do Noroeste peninsular, que será a base de partida de todas as posteriores e que está nos alicerces mesmos da nosa comprensión actual do territorio galego. Non dispoñemos dos instrumentos nin dos coñecementos precisos para establecer unha correlación entre este proceso histórico e o mapa dialectal do galego histórico e actual, se ben, persoalmente, pensamos que se trata dun fenómeno bastante posterior no tempo ao período que temos estudado, para o que non existen datos ao respecto. Mais o tema das orixes altomedievais da comarcalización de Galicia non ten un interese exclusivamente anticuario, non é algo pertencente a un pasado moi afastado e extinto. De feito, como poderiamos amosar se dispuxeramos dun tempo e dun espazo menos limitados, o deseño territorial da Galicia altomedieval segue operativo na actualidade: virtualmente, todas as denominacións comarcais que estudamos teñen vixencia hoxe en día, como bisbarras, concellos, arciprestados ou parroquias. Falamos dun tempo, unha terra e unha xente que xa non son, pero non esquezamos -xeógrafos, historiadores e filólogos- que sen eles o noso tempo, a nosa terra e a nosa xente nin serían, nin poderían ser entendidos.

\footnotetext{
${ }^{14}$ Cf. 910-06-7, Tumbo Vello de Lugo, ff. 36v-37r.
} 